\title{
Grasping the Global and the Local in Memorialisation Practices. Some Dialogues and Tensions between Latin America and Europe
}

\author{
ESTELA SCHIN DEL \\ Universität Konstanz, 78457, Konstanz, Germany. E-mail: estela.schindel@ \\ uni-konstanz.de
}

Theses about globalised, cosmopolitan, transnational or multilateral memories have received wide circulation over the past few decades. However, their reception in - and pertinence to - Latin America has up to now received little attention within the international debate. This article aims to contribute to this debate by focusing on the particular field of memorialisation discourses and practices. The text posits the existence of a certain global memorialising language, characterised by particular aesthetic and architectonic features. These traits are placed in contrast and in dialogue with the rich memorial tradition that has developed in Argentina since the 1970 s, led by the human rights movement and its supporters.

During the past few decades, memory of the Holocaust has been the object of a manifold circulation, reception and re-appropriation in the globalised world. According to Andreas Huyssen, we are witness to a 'globalization of the Holocaust discourse', whose memory has developed into a metaphor for other traumatic histories and their memories, acquiring a global dimension and being adapted to local events, which are historically and politically distant. ${ }^{1}$ While Huyssen sees the implicit risk of obscuring the importance of local histories critically, Daniel Levy and Natan Sznaider consider this tendency as the coming of a cosmopolitan memory, in which culture and politics are increasingly de-localised and national memory cultures lose importance. ${ }^{2}$ More recently, Michael Rothberg has suggested the notion of multidirectional memories, where the cultural productions related to the elaboration of the Holocaust intersect with the perspective of the postcolonial studies in the broader frame of decolonization processes. ${ }^{3}$

Whether and to what extent these theses apply to the case of Latin American has been little explored so far. This article aims to contribute to that goal by discussing the 
local production and reception of global tendencies in some memorialising initiatives of the last Argentinean dictatorship (1976-1983). Some memorial practices undertaken in the Southern Cone offer a privileged field to observe the dialogue and mutual perceptions between the Latin American and the European memorial landscapes. However, and in spite of their richness and originality, they have until now received little attention in international discussion. How do memorial patterns related to Holocaust memory circulate in Latin American post-dictatorship contexts? How are the Holocaust discourses received and re-appropriated through national memories? And how are the local and the global entangled and interwoven in these practices? This article does not aim at offering definitive answers to these questions, but to reflect upon them from a concrete Argentinean case and by considering the influx of European discourses and actors on this case.

Global memories are not received in a void, but according to the historical context, the political aspirations and the needs prevailing in a certain society. Local contingencies inform the way in which such global discourses are perceived, elaborated and transmitted. A closer look at the reception of the Holocaust in the Latin American intellectual field reveals the influence of such local developments. An initial inquiry about this evolution - which further research shall confront and deepen - reveals slightly different patterns than those proposed by Rothberg and by Levy/Sznaider about the circulation of Holocaust discourses - and suggests that, rather than operating in a universal, unilateral way, they deliver a pattern of interpretation when and if they have something to say to the local needs. ${ }^{4}$ In the immediate post-war period, between 1945 and 1950 approximately, Latin American intellectuals did not yet deal with the Holocaust as such, but with the impact of the Second World War and its crimes as a whole. The shock regarding the crimes of the war moved local intellectuals to express their position with their own regional voice. From this perspective, Nazism and genocide were seen in relation to the role that Latin America as a young, vibrant continent should play after the European collapse. This awareness was, however, followed by a 'cold' phase, ranging from 1950 until around 1980, when the Holocaust remained rather absent from the political and cultural agenda. In spite of the connections to the decolonising movements that Rothberg identifies in other geographies, the Holocaust seemed to have less to say to a Latin America mostly concerned with overcoming the structural dependency of their countries, either by following the development paradigm (desarrollismo) or supporting the revolutionary cause - none of which appeared compatible with a reflection upon the legacy of the Shoah.

It is only after the 1980s that the Holocaust reappeared in public discussion, coinciding with the end of the dictatorships in several South American countries, and the literature linked the discourses on the dictatorships with the elaboration of the countries' own difficult pasts. Mass murder and disappearances aroused a series of questions that had already been posed in relation to the trauma of the Holocaust and its legacies. The crisis of representation and witnessing in the face of extreme horror, the quest for justice for crimes that are beyond reparation, the search for alternative strategies for remembering the dead when there are no graves, and the challenges of education and transmission of such historical wrongs are issues for which the experience of the Holocaust had produced 
a large corpus of work on which to draw. Patterns developed in the European context were read and extrapolated to South America, delivering a frame of reference for understanding what had happened and how it should be remembered.

\section{A Global Language of Memorialisation?}

The growing presence of Holocaust discourses in the globalised world goes together with what many authors consider a more generalised 'memory boom' over the last few decades: a growing interest in archives, revivals and vintage trends, which testifies to an obsession to register and record the past. This hypertrophy of memory has been interpreted as a symptom of the passage from an 'organic' memory to an archival one, which lies on repository artefacts and would reveal as much an interest in the past as the incapability of imagining the future. ${ }^{5}$

It is in this context that memorials, museums, public sculptures and commemorative sites have experienced a renewed life and currently proliferate in the urban space. These contemporary monuments break radically with the tradition of exalting victories and glorifying heroes of previous centuries, when they were attached to the founding narratives of the Nation State, as characterised in Pierre Nora's classic work about the lieux de memoire. After the Second World War, France and Germany constructed memorials that operate as admissions of a failure on the part of the nation or as pedagogical artefacts from which to learn. ${ }^{6}$ This new generation of memorials consequently dismisses the univocal and grandiloquent rhetorical language of former commemorative monuments and has more challenging aesthetical resources. If glorifying sculptures were erected to convey stable messages, the new memorials are aimed at destabilising meanings; rather than tranquilising the visitor they attempt to disturb; they do not propagate a truth in an authoritarian or unilateral way, but interpellate the viewer, inviting him or her to complete the meaning through an active reception; they do not consummate but question the very possibility of memory. Such memorials do not necessarily integrate into the urban landscape in a harmonious way but prefer to point out at its ruptures and discontinuities. The creativity and audacity of some artistic approaches evoking the Holocaust in this manner, resolutely leaving behind traditional memorial art, led James Young to define them as 'counter monuments' in his already canonical work. ${ }^{7}$

An analogous movement took place in the museums, which in the last few decades developed more participative or interactive designs. In the new concept the visitors are not meant to just acquire information, but to live an experience. The goal is not just to transport contents but to generate sensations and mobilise the visitor. The museums' architecture relies on elements such as glass, aluminium or wood, replacing the more traditionally solid and opaque materials, and preferring abstract forms to straight, univocal messages. As in the newer commemorative monuments, their language neglects figurative depictions and irregular forms are preferred to harmony and symmetry.

The US Holocaust Memorial Museum, inaugurated in Washington in 1993, was the first big institution committed to the subject to draw on such a concept. 
The architect wanted the building to act itself as 'a resonator of memory' for the visitors to make their own interpretations and experience the building 'viscerally'. James Freed's 'architecture of sensibility' was not meant to be intellectually understood but to 'engage the visitor and stir the emotions, allow for horror and sadness, ultimately to disturb' ${ }^{8}$ The Holocaust Museum gave way to a new approach in memorial architecture and art and many commemorative sites adopted - or adapted to - this trend. The Berliner Memorial to the Murdered Jews of Europe, which opened to the public in 2005 after a decade of debate, was conceived by Peter Eisenman so as to unsettle the visitors who stroll through the 2711 concrete slabs of the 'Field of Stelae'. The other most iconic memorial exponent in the German capital - Daniel Libeskind's Jewish Museum Berlin - is a building saturated with symbols, prominently the 'void', and structured along three axes (exile, annihilation and continuity) supposed to generate a sensorial insight into the fate of German Jews. If there is something like a globalised memorial discourse, these two works are its most paradigmatic expressions: a transnational aesthetic language originating in the context of the Holocaust memory and informed by anti-memorial gestures that are becoming global and increasingly quoted and reproduced beyond their countries of origin.

A recent incarnation of this trend, Warsaw's new Museum of the History of the Polish Jews stands physically opposing - and conceptually contrasting - Nathan Rapoport's iconic monument that commemorates the Warsaw Ghetto Uprising: on the one side there is a figurative representation of resistance exalting heroic values; on the other, a coexistence of polyvalent symbols, drawing on much of the abstract tendencies of memorial architecture mentioned above. Here it is not about straight, broken lines as in Libeskind's piece, but by undulating, suggestive walls, as if trying to embrace and offer a home to the dramatic legacy of Polish-Jewish history. But again it is the sculptural space itself that is meant to commove. The entry, a curved passageway in the form of a canyon, has been interpreted as an image of abrupt rupture or as a figure of the biblical partition of the Red Sea. The building opened to the public in April 2013, timely for the 70th Anniversary of the Ghetto uprising, but without featuring the core collection, which was still in preparation. The public could then visit a temporary exhibition, and - of course - the cafeteria and shop, which have acquired a growing importance in today's globalised museums.

The opening of the museum's building before displaying the main exhibition, as had happened also with the Jewish Museum in Berlin in 2001, may be symptomatic for the self-referential quality of many contemporary memorials. As if it were the Museum's enunciation of itself, the very staging of memory, that is foregrounded, leaving the content to fill it as a secondary movement. Rather than being mere houses hosting a collection, the buildings themselves - and often their architects - play the starring role. This self-referential gesture, with the architecture at the centre referring to its own symbolism and skills, is a prominent feature of many contemporary memorial works. Could this be an additional expression of the globalised character of memory? A transnational memorial language that originated for the commemoration of the Holocaust but replied, with similar formulae and aesthetic resources, in other 
geographies, detached from their localised contexts and specific historical contents? In the following analysis, I will attempt to explore these questions, contrasting them with the example of Argentinean post-dictatorship art.

\section{Performative Practices of Remembering}

Latin American initiatives to commemorate State terror crimes give testimony for both a reception of such global tendencies and for the existence of an own, specific language of memory. The building of the National Museum of Memory in Santiago de Chile inaugurated in 2010, for example, quotes many of the features described above, putting the institution in the frame of the memorial tendencies of the global memory age: its glassed external walls crossed by broken, discontinuous lines that echo Libeskind's famous building, and deprived of an apparent order, convey that history cannot be told following an ordered script, that there are no unique interpretations, but irregular fragments and ruptures.

Decades before, in Argentina, a constellation of singular performative practices, symbols and icons developed alongside the human rights movement and, especially, the Mothers of Plaza de Mayo. The mothers of the disappeared were the pioneers and main source of inspiration for these innovative practices. When they started protesting publicly in 1977 against the abduction of their children and demanding information about their children's whereabouts, they became themselves the moral and material support of the memory of the disappeared. Their weekly demonstrations in the square after which they are named turned the search for their sons and daughters into a way of making their children's absences visible in the heart of the capital. Moved by affect, they occupied the central space of Argentinean public life, in an effective, peaceful and powerful performance of embodied, living memory which was (and indeed continues to be) exemplary.

The artists and activists that accompanied their struggle during and after the dictatorship continued along the path of bringing the protest to public space and developed participative strategies with which to achieve it. The most memorable of these, the 'Siluetazo' (or Silhouette campaign), in December 1983, consisted of pasting life-size silhouettes of men and women onto the walls of Buenos Aires, as a means of symbolically re-including the ghostly presence of the disappeared in the city landscape. An interesting case for the productive dialogue of memories, the creators of the Siluetazo had found inspiration in a work by polish artist Jerzy Skapski, who wanted to raise, on a lower scale, the question of how much space the number of persons killed in Auschwitz every single day would fill. In the Argentinean re-elaboration of the concept though, the installation was not in a gallery but out on the streets, and the collective making of the silhouettes took the action far beyond the notion of the individual work of art. The silhouettes were produced during a demonstration and its participants served as 'models' lending their bodies to serve as patterns for drawing them: a powerful way of engaging themselves with the action, which blurred the limits between politics and art, and between work and action. ${ }^{9}$ In a similar spirit, the campaign 'Dele una mano a los desaparecidos' ('Give a hand to the disappeared') installed chains 
of paper with the drawn outlines of the demonstrators' own hands across a main avenue in Buenos Aires, as if aiming to contact and touch those who are absent. Silhouettes and hands multiplied the individual trace and made it collective. This collective dimension brings such experiences closer to the political realm and differentiates them from initiatives undertaken in other geographical contexts, which often follow more institutional channels: the 'baldosas de la memoria' ('floor tiles for memory') installed on many pavements of Argentinean cities resemble the Stumbling Stones produced by Günter Demnig to mark the former dwellings of victims of the Holocaust on German pavements, only that in the South American version they are not made by an individual artist but by groups of neighbours and activists.

In these experiences, the borders between art, protest and performance seem to blur. However, they should not be understood as the result of calculated strategies of political communication or a deliberate mise-en-scène. Rather, they developed out of the practice and were originally answers to very urgent needs. Standing at the Plaza de Mayo was not a tactical manoeuvre by the mothers of the disappeared but a direct reaction after not finding an answer at Government House, situated opposite. When the police tried to disperse the demonstration, ordering them to 'circulate', they spontaneously started to walk around the pyramid at the centre of the square, giving birth to their legendary rounds. Their white scarves were used for the first time during a religious peregrination in 1979 as a way to distinguish and find themselves among the multitude. Originally a nappy, the piece was chosen primarily not for its powerful symbolic meaning, but for a pragmatic reason: it is an object that every mother would have conserved at home as a piece of remembrance. That the plaza, pyramid and white scarf became such strong political symbols in Argentinean political life is not due to a previous intentionality but the result of a slow social construction made out of little gestures and local practices over the course of several decades.

\section{Argentina's Parque de la Memoria: Conflating the Local and the Global}

The case of the Argentinean Parque de la Memoria, upon which we now focus, places in evidence in a very illuminating way the productive tension between patterns that circulate globally and the legacy and tradition of local political and cultural practices.

The creation of a space of memory that included all the names of the disappeared and those murdered by State terrorism had been a long claim of human rights organisations and relatives of the victims, who longed for an official centralised space to honour their memories. Other actors involved with the elaboration of the dictatorial past, such as one sector of the Mothers of Plaza de Mayo, feared instead that the monument could contribute to a certain petrification or over-institutionalising of the legacy of the disappeared. The monument was finally inaugurated in 2007 and was accompanied by a covered space for exhibitions and a Sculpture Park. The monument of the names, the core of the project, was conceived as an open wound on the earth, following the wish of the disappeared families that it should not evoke a closed scar. Four huge blocks of concrete contain the names of the disappeared on easily removable plaques, leaving space for names that will become known in the 
future. In the already-mentioned essay, Andreas Huyssen considers the wall containing the victims' names an evocation of Maya Ling's Vietnam War Veterans' Memorial in Washington and its broken-line shape an echo of the zigzag contour of the emblematic Jewish Museum Berlin. The project is for Huyssen a case of productive inscription and creative appropriation of certain tropes and images whereupon the Holocaust functions like an international prism that helps to focus the local memories. By drawing on two contemporary icons of memory culture, he argues, the Argentinean monument can be read in the larger context of a now international culture of memory and as an example of how local cultural discourses are increasingly inflected by global practices.

Long before the monument with the names was ready, in 1999, an international competition was opened for the sculptures to be constructed in the park. The entries compose, as a whole, an interesting ensemble that brings together local artists and activists with some important names of the global art circuit. ${ }^{10}$ It is significant that many projects by Argentinean authors somehow quote, recreate or honour those iconic elements that have characterised the human rights' movement struggle, such as the white scarves of the mothers or the pictures used at their demonstrations, now translated into solid materials thus posing the paradox of fixing live symbols into more stable settings. Some works selected by the jury and already constructed manage creatively to combine and mingle both approaches. The sculpture of Nicolas Guagnini, an artist and son of a disappeared, is a three-dimensional variation of the photograph of his father that his grandmother used to carry in the demonstrations. The piece by Roberto Aizemberg, featuring three hollow figures, can be read as a quotation of the famous 'silhouettes', now emigrated from the ephemeral quality of paper into the permanency of iron. A third example, the installation 'Signposts of memory', was originated in the work of the GAC or Grupo de Arte Callejero (Street Art Group) while accompanying the demonstrations of children of the disappeared against repressors' domiciles. Imitating the format of traffic signals, these signposts would point at former detention centres or at the houses of military personnel, as a way of turning the ubiquity of the traces left by State terror visible in the urban space. Away from the authentic sites linked to the disappearances, they certainly run the risk of losing intensity; the spontaneous and dynamic character of the original actions were thus neutralised. However, the memorialisation of such icons does not need to be posed in terms of contradictions, but can be understood as a fertile dialogue: the testimony of a memory culture that acknowledges the achievements of decades of human rights campaigning.

During the process of collecting proposals for the sculptures two board members of the Parque de la Memoria met in Paris with the French-Polish artist Christian Boltanski in order to invite him to participate with a work of his own. Boltanski, however, declined the invitation saying that he was sceptical about the real possibilities of such memorials. France is full of plaques commemorating the dead of the world wars, he said, but nobody really pays attention to them. He suggested that it would be more meaningful to initiate another kind of action, such as publishing ads in the newspapers remembering the disappeared every day. ${ }^{11}$ Boltanski did not know 
that this idea had already been developed in Argentina, where such pieces have been published in the daily Página/12 since 1987. The anecdote illustrates the potential and originality of the resources invented by relatives and friends of the disappeared to honour their memory. While in the European context the challenge is to create dynamic or participative memorial projects, deconstructing official narratives and decentring state monuments in order to include the commemoration in everyday life, the anecdote recalls that some of those traits might already have been part of the Argentinean memory traditions without its protagonists necessarily being aware. The publication of these small homages to the disappeared though had not arisen out of an artistic impulse or an academic reflection, but from the need to find alternatives to the traditional mourning rituals for the graveless dead. Concerned with giving international visibility to the Parque de la Memoria and including it in the circuits and codes of the global language of memory, the organisers might have dismissed the potential of the country's own memory culture, which has only briefly been sketched out here, but deploys a richness worth exploring when analysing the dynamic interactions between memorial cultures.

Qualities that are celebrated in the European context, such as the promotion of decentralised, dynamic and active memories in the public space, may have been largely part of the practices and actions of the Argentinean human rights movement but, as with this example, have not been perceived as art. Their value may lie precisely in the fact that they are not the result of deliberated strategies, either by experts or functionaries, but the fruit of initiatives stemming from the concrete practices of social actors or political action. Such initiatives are not exempt from conflicts and contradictions and should not be idealised, but neither should they be underestimated in their potential for fostering participative memories and promoting an active confrontation with the legacies of history. Beyond the quotes, references or creative appropriation of global memorial languages and patterns, it is only in the engaged consciousness of citizens where the memory of those who were forcefully rendered absent can persistently dwell.

\section{References}

1. A. Huyssen (2003) Present Pasts. Urban Palimpsests and the Politics of Memory (Stanford: Stanford University Press).

2. D. Levy and N. Sznaider (2006) The Holocaust and Memory in the Global Age (Philadelphia: Temple University Press).

3. M. Rothberg (2009) Multidirectional Memory: Remembering the Holocaust in the Age of Decolonization (Stanford: Stanford University Press).

4. E. Schindel (2005) Los intelectuales latinoamericanos y el Holocausto: notas para una investigación. In: S. Carreras, (Ed.), Der Nationalsozialismus und Lateinamerika. Institutionen, Repräsentationen, Wissenskonstrukte (II) (Ibero-Online.de 3-II), pp. 2-35.

5. R. Terdiman (1993) Present Past: Modernity and the Memory Crisis (Ithaca: Cornell University Press).

6. P. Carrier (2005) Holocaust Monuments and National Memory Cultures in France and Germany since 1989. Origins and Political Function of the Vél d'Hiv in Paris and the Holocaust Monument in Berlin (Oxford, New York: Berghahn). 
7. J. Young (1993) The Texture of Memory. Holocaust Memorials and Meaning (New Haven, London: Yale University Press).

8. http://www.ushmm.org/museum/a_and_a/ (accessed August 20, 2013).

9. A. Longoni, G. Bruzzone (Eds) (2006) El Siluetazo (Buenos Aires: Adriana Hidalgo).

10. Comisión Pro Monumento a las Víctimas del Terrorismo de Estado (2001) Escultura y Memoria (Buenos Aires: Eudeba).

11. G. Bruzzone (2001) La obra de Boltanski ya realizada por Página/12. Ramona. Revista de artes visuales, 19/20, p. 81.

\section{About the Author}

Estela Schindel is a Postdoctoral Researcher and Scientific Coordinator on the PhD Programme entitled 'Europe in the Globalized World' at the Center of Excellence 'Cultural Foundations of Social Integration', University of Konstanz, Germany. She has co-edited the volumes Urbane Erinnerungskulturen im Dialog: Berlin und Buenos Aires (Metropol Verlag, 2009) and Memorias Urbanas en Diálogo: Berlín y Buenos Aires (Buenos Libros/Fundación Böll, 2010). 